\title{
Depressive symptoms and cardiovascular diseases in the adult Polish population. Results of the NATPOL2011 study
}

\author{
Jerzy Piwoński ${ }^{1}$, Aleksandra Piwońska ${ }^{1}$, Piotr Jędrusik², Jakub Stokwiszewski ${ }^{3}$, \\ Marcin Rutkowski ${ }^{4}$, Piotr Bandosz ${ }^{4}$, Wojciech Drygas ${ }^{1,5}$, Tomasz Zdrojewski ${ }^{4}$ \\ ${ }^{1}$ Department of Epidemiology, Cardiovascular Disease Prevention, and Health Promotion, Institute of Cardiology, Warsaw, Poland \\ ${ }^{2}$ Department of Internal Medicine and Hypertension, Medical University of Warsaw, Warsaw, Poland \\ ${ }^{3}$ National Institute of Public Health - National Institute of Hygiene, Warsaw, Poland \\ ${ }^{4}$ Department of Hypertension and Diabetology, Medical University of Gdansk, Gdansk, Poland \\ ${ }^{5}$ Department of Social and Preventive Medicine, Medical University of Lodz, Lodz, Poland
}

\begin{abstract}
A b stract
Background: Poland is a country of high cardiovascular risk. Because depression was found to be a predictor of coronary artery disease and the prevalence of depressive symptoms (DSs) has risen worldwide, their monitoring in the population is desirable.

Aim: We sought to evaluate the prevalence of DSs in relation to the socio-demographic status and selected types of cardiovascular diseases in the adult Polish population.

Methods: A country-representative random sample of 2413 subjects, aged 18 to 79 years, was examined in 2011. Rates of self-reported cardiovascular conditions including hypertension (HT), coronary artery disease (CAD), previous myocardial infarction (MI), heart failure, atrial fibrillation (AF), and stroke were assessed by a questionnaire, and the prevalence of DSs was assessed by Beck Depression Inventory (BDI), separately in men and women. DSs were defined as BDI score $\geq 10$ points.

Results: Depressive symptoms were found in $23.4 \%$ of men and $33.4 \%$ of women $(p<0.0001$ ). The prevalence of DSs increased with age, from $16.5 \%$ in the youngest group of men to $48.3 \%$ in the oldest group of women. We found that DSs were significantly more prevalent in subjects suffering from $\mathrm{HT}, \mathrm{CAD}$, stroke, $\mathrm{AF}$, and diabetes, and also in women after MI. The rates of DSs in women with a history of $\mathrm{MI}$ or stroke were extremely high $(76.3 \%$ and $83.3 \%$, respectively). Age and primary education level were associated with DSs, as was history of stroke in women. DSs were more often found in older persons and in those with primary level of education.

Conclusions: Depressive symptoms were more prevalent in women compared to men, and they were significantly and independently associated with age and primary education level in both sexes, and with a history of stroke in women.
\end{abstract}

Key words: Beck Depression Inventory, cardiovascular diseases, cross-sectional survey, depressive symptoms, sociodemographic factors

Kardiol Pol 2019; 77, 1: 18-23

\section{INTRODUCTION}

Cardiovascular diseases (CVDs) are a major health, social, and economic problem in Poland. They were the major cause of premature mortality (below 65 years of age) in the Polish population. In 2010, CVDs were the cause of $46 \%$ of all deaths in Poland [1]. The number of deaths due to CVD in Poland has gradually decreased since 1991, but it remains among the highest in Europe. The pathogenesis of atherosclerosis that leads to CVD is complex and not fully understood, but, in addition to conventional risk factors (hypertension, smoking, hyperlipidaemia), psychosocial factors are also considered independent contributors to cardiovascular risk [2]. Regarding the role in CVD pathophysiology, the most important psychosocial factors include chronic stress, low social support,

\section{Address for correspondence:}

Jerzy Piwoński, MD, PhD, Department of Epidemiology, Cardiovascular Diseases Prevention, and Health Promotion, The Cardinal Stefan Wyszynski Institute of Cardiology, ul. Alpejska 42, 04-628 Warszawa, Poland, tel: +48 228156556 int. 206, fax: +48 22812 5586, e-mail: jpiwonski@ikard.pl

Received: 23.07.2018 Accepted: 31.10.2018 Available as AoP: 31.10.2018 
and depression. Depression as a psychosomatic disorder was found to be an independent predictor of coronary artery disease (CAD) [3]. It was shown that a history of at least one episode of depression is associated with a fourfold increase in the risk of myocardial infarction (MI) [4]. Thus, an assessment of the prevalence of depressive symptoms (DSs) in the general population seems of no less importance than the evaluation of the prevalence of conventional CVD risk factors.

The aim of the present study was to evaluate the prevalence of DSs in the general adult Polish population in relation to the sociodemographic status, place of residence, and selected types of CVD, based on the NATPOL2011 study findings.

\section{METHODS}

\section{Study population and methods of sampling}

The 2011 National Polish Study to Evaluate the Prevalence of Cardiovascular Disease Risk Factors (NATPOL2011) was designed as a representative cross-sectional survey of the Polish population aged 18 to 79 years. Participants were randomly selected in territorial bundles of 11 subjects on average, with stratification according to the place of residence, age, and sex. Sampling was performed at the Department of State Registers at the Ministry of the Interior using the electronic PESEL population registry. A detailed description of the NATPOL2011 study methods was reported previously [5]. The study was planned, designed, and conducted by the Department of Hypertension and Diabetology at the Medical University of Gdansk in cooperation with the Medical University of Warsaw and the National Institute of Cardiology in Warsaw [5].

The NATPOL2011 study included 2413 subjects (51.3\% women). The present study was based on the sample of 2224 subjects (51.3\% women) who filled in the psychological questionnaire. The respondents were examined by 234 trained nurses and the response rate was $67 \%$. The study included a questionnaire interview, anthropometric measurements, blood pressure measurements (during two visits), and biochemical testing.

For the purpose of the present study, we identified subjects with hypertension, CAD, a history of $\mathrm{MI}$ or stroke, diabetics, and smokers. Hypertension was defined as a mean blood pressure of $\geq 140 \mathrm{mmHg}$ systolic or $\geq 90 \mathrm{mmHg}$ diastolic calculated from four measurements during two visits, or the use of antihypertensive medications. Subjects with a history of diabetes or with fasting blood glucose level $\geq 7.0 \mathrm{mmol} / \mathrm{L}$ were considered diabetic. The diagnoses of CAD, previous $\mathrm{MI}$, and previous stroke were based on data from past medical records. Subjects who smoked at least one cigarette per $24 \mathrm{~h}$ were considered smokers.

\section{Evaluation of depressive symptoms}

The study subjects filled in, among other questionnaires, a 1961 version of the Beck Depression Inventory (BDI) to evaluate the presence of DSs. The BDI questionnaire includes
21 items, rated by the respondent on a scale of $0-3$, depending on the symptom severity. The presence of DSs was defined as a score of 10 or higher [6].

\section{Statistical analysis}

All analyses were performed separately for men and women. The results were expressed as percentages. The $\chi^{2}$ test was used to compare the rates of DSs in different sociodemographic groups and subsets defined by the concomitant conditions. Statistical significance was set at $p<0.05$. To identify factors associated with DSs, we performed multivariate logistic regression analysis in a model that included sociodemographic variables (age, education level, marital status), place of residence, and selected concomitant conditions (CAD, hypertension, obesity, previous stroke). Analyses were performed using the IBM SPSS Statistic Package (V19, Poland).

\section{RESULTS}

The characteristics of the study subjects who participated in the psychological NATPOL2011 sub-study are shown in Table 1. Most respondents were younger than 60 years of age, had completed at least secondary education, and had a spouse or a partner. Depressive symptoms were present in $23.4 \%$ of men and $33.4 \%$ of women.

When analysing the sociodemographic status of the study subjects in relation to DSs, we found that their prevalence increased significantly with the respondent's age. In subjects above 60 years of age, DSs were about twice as prevalent as in subjects below 40 years of age. In addition, the rate of DSs was inversely proportional to the education level. In both men and women with higher education, DSs were about half as prevalent as in subjects with primary or secondary vocational education. Marital status had a significant effect on the rate of DSs only in women. We found DSs to be most prevalent among divorced or widowed women (Table 2).

When we analysed the rates of DSs in subjects with selected concomitant conditions, we found that they were significantly more prevalent in subjects with hypertension, diabetes, CAD, heart failure, atrial fibrillation (AF), and a history of stroke as well as in women with a history of MI. Of note, DSs were particularly frequent in women with a history of stroke (83.3\%) or MI (76.9\%) (Table 3 ).

Logistic regression analysis showed that the only sociodemographic characteristics that showed a significant association with DSs in both sexes were age and primary education level (Table 4); the likelihood of DSs occurrence increased with age and it was also about twice as high in men and women with primary education as in those with higher education.

Despite a significantly higher prevalence of DSs in both men and women with selected concomitant conditions, logistic regression analysis did not show a significant association between DSs and any of these conditions in men, with a borderline association with hypertension. In women, DSs were strongly and significantly related to stroke (odds ratio 
Table 1. Characteristics of the study subjects who participated in the psychological NATPOL2011 sub-study

\begin{tabular}{|c|c|c|c|c|}
\hline Characteristics of the study subjects & Men $(n=1084)$ & $\mathbf{p}$ & Women $(n=1140)$ & p \\
\hline Age [years]: & & $<0.0001$ & & $<0.0001$ \\
\hline $18-39$ & $485(44.8)$ & & $491(43.1)$ & \\
\hline $40-59$ & $416(38.4)$ & & $415(36.4)$ & \\
\hline $60-79$ & $182(16.8)$ & & $234(20.5)$ & \\
\hline Level of education: & & $<0.0001$ & & $<0.0001$ \\
\hline Primary/vocational & $469(43.3)$ & & $344(30.2)$ & \\
\hline Secondary & $399(36.8)$ & & $447(39.3)$ & \\
\hline Higher/incomplete higher & $215(19.9)$ & & $347(30.5)$ & \\
\hline Place of residence: & & NS & & NS \\
\hline Rural area & $399(36.8)$ & & $272(32.6)$ & \\
\hline Small town $(<50,000$ inhabitants $)$ & $271(25.0)$ & & $388(34.0)$ & \\
\hline Medium-sized city $(50,000-200,000$ inhabitants) & $214(19.7)$ & & $203(17.8)$ & \\
\hline Large city (> 200,000 inhabitants) & $201(18.5)$ & & $277(24.3)$ & \\
\hline Marital status: & & $<0.0001$ & & $<0.0001$ \\
\hline Single & $303(27.9)$ & & $281(24.7)$ & \\
\hline Married & $707(65.2)$ & & $635(55.7)$ & \\
\hline Divorced/separated & $45(4.1)$ & & $91(8.0)$ & \\
\hline Widowed & $30(2.8)$ & & $132(11.6)$ & \\
\hline Presence of depressive symptoms & $254(23.4)$ & & $381(33.4)$ & $<0.0001$ \\
\hline
\end{tabular}

Data are shown as number (percentage). NS — non-significant

Table 2. Rates of depressive symptoms in relation to the sociodemographic status and sex

\begin{tabular}{|c|c|c|c|c|}
\hline \multirow[t]{2}{*}{ Socioeconomic status } & \multicolumn{4}{|c|}{ Depressive symptoms } \\
\hline & Men $(n=1084)$ & $\mathbf{p}$ & Women $(n=1140)$ & p \\
\hline Age [years]: & & $<0.0001$ & & $<0.0001$ \\
\hline $18-39$ & 16.5 & & 23.8 & \\
\hline $40-59$ & 27.9 & & 36.4 & \\
\hline $60-79$ & 31.3 & & 48.3 & \\
\hline Level of education: & & $<0.0001$ & & $<0.0001$ \\
\hline Primary/vocational & 30.1 & & 44.5 & \\
\hline Secondary & 20.6 & & 31.8 & \\
\hline Higher/incomplete higher & 14.0 & & 24.5 & \\
\hline Place of residence: & & NS & & NS \\
\hline Rural area & 23.3 & & 34.9 & \\
\hline Small town $(<50,000$ inhabitants $)$ & 22.9 & & 35.1 & \\
\hline Medium-sized city $(50,000-200,000$ inhabitants) & 20.6 & & 30.5 & \\
\hline Large city (> 200,000 inhabitants) & 27.4 & & 32.1 & \\
\hline Marital status: & & NS & & $<0.0001$ \\
\hline Single & 19.8 & & 28.8 & \\
\hline Married & 25.2 & & 29.8 & \\
\hline Divorced/separated & 17.8 & & 41.8 & \\
\hline Widowed & 26.7 & & 55.3 & \\
\hline
\end{tabular}

Data are shown as percentage. NS - non-significant 
Table 3. Rates of depressive symptoms (DSs) in subjects with selected concomitant conditions

\begin{tabular}{|c|c|c|c|c|c|c|}
\hline \multirow[t]{2}{*}{ Condition } & \multicolumn{3}{|c|}{ Men $(n=1084)$} & \multicolumn{3}{|c|}{ Women $(n=1140)$} \\
\hline & DSs (+) & DSs (-) & p & DSs (+) & DSs (-) & p \\
\hline Hypertension (N: M - 398; W-346) & 31.3 & 18.9 & $<0.001$ & 45.1 & 29.0 & $<0.001$ \\
\hline Coronary artery disease $(\mathrm{N}: \mathrm{M}-58 ; \mathrm{W}-84)$ & 37.2 & 22.9 & $<0.01$ & 47.7 & 32.2 & $<0.001$ \\
\hline Previous myocardial infarction (N: $\mathrm{M}-44, \mathrm{~W}-17)$ & 30.3 & 23.1 & NS & 76.9 & 32.9 & $<0.001$ \\
\hline Atrial fibrillation (N: $M-57, W-67)$ & 43.4 & 22.4 & $<0.001$ & 49.3 & 32.4 & $<0.01$ \\
\hline Previous stroke (N: $\mathrm{M}-30, \mathrm{~W}-20)$ & 47.8 & 22.8 & $<0.01$ & 83.3 & 32.9 & $<0.001$ \\
\hline Diabetes $(\mathrm{N}: \mathrm{M}-56, \mathrm{~W}-56)$ & 38.6 & 22.8 & $<0.01$ & 49.3 & 32.4 & $<0.001$ \\
\hline Obesity (N: M - 249, W - 221) & 28.4 & 17.8 & NS & 53.8 & 26.1 & $<0.001$ \\
\hline
\end{tabular}

Data are shown as percentage. NS — non-significant; $\mathrm{M}$ - men; $\mathrm{W}$ - women; $\mathrm{N}$ - number

Table 4. Associations between depressive symptoms and socio-demographic variables and selected concomitant conditions (multivariate logistic regression model)

\begin{tabular}{|c|c|c|c|c|c|c|}
\hline \multirow[t]{2}{*}{ Variable } & \multicolumn{3}{|c|}{ Men } & \multicolumn{3}{|c|}{ Women } \\
\hline & OR & $95 \% \mathrm{Cl}$ & $\mathbf{p}$ & OR & $95 \% \mathrm{Cl}$ & $\mathbf{p}$ \\
\hline Age (per 10-year increase) & 1.24 & $1.04-1.48$ & 0.015 & 1.27 & $1.10-1.47$ & 0.001 \\
\hline \multicolumn{7}{|l|}{ Marital status: } \\
\hline Married & 1.00 & & & 1.00 & & \\
\hline Divorced & 0.59 & $0.24-1.47$ & NS & 1.66 & $0.97-2.82$ & NS \\
\hline Widowed & 0.60 & $0.24-1.49$ & NS & 1.76 & $0.99-3.14$ & NS \\
\hline Single & 1.31 & $0.72-2.37$ & NS & 1.57 & $0.99-2.47$ & NS \\
\hline \multicolumn{7}{|l|}{ Level of education: } \\
\hline Higher & 1.00 & & & 1.00 & & \\
\hline Primary & 2.26 & $1.34-3.81$ & 0.002 & 1.96 & $1.24-3.11$ & 0.004 \\
\hline Secondary & 1.59 & $0.89-2.85$ & NS & 1.30 & $0.90-1.88$ & NS \\
\hline Hypertension & 1.41 & $0.96-2.08$ & NS & 1.03 & $0.71-1.52$ & NS \\
\hline$C A D$ & 0.88 & $0.42-1.87$ & NS & 0.80 & $0.26-2.44$ & NS \\
\hline Stroke & 1.63 & $0.61-4.34$ & NS & 6.07 & $1.88-19.53$ & 0.003 \\
\hline Atrial fibrillation & 1.59 & $0.64-3.91$ & NS & 1.33 & $0.75-2.36$ & NS \\
\hline
\end{tabular}

CAD — coronary artery disease; CI — confidence interval; OR — odds ratio; NS — non-significant

[OR] 6.07; 95\% confidence interval [CI] 1.82-19.4), regardless of age, sociodemographic status, and other concomitant conditions, including AF (Table 4).

\section{DISCUSSION}

The NATPOL2011 study allowed the evaluation of the prevalence of DSs in the adult Polish population and their association with the socio-demographic factors. In addition, a significant association was found between a history of stroke and the presence of DSs in women.

Depression is probably the most common psychiatric condition that remains underdiagnosed in clinical practice. In the NATPOL2011 study, we found DSs to be present in $23.4 \%$ of men and $33.8 \%$ of women. Similar rates of DSs in the general population ( $24 \%$ in men and $34 \%$ in women) were found using the same questionnaire in another nationwide Polish study, the WOBASZ study, in the years 2003 to 2005 [7]. Compared to other European countries, the rates of DSs in Poland are similar to those reported for Northwestern European countries, although methodological differences should be taken into account (the use of data restricted to past medical records or the use of a depression scale other than that employed in the NATPOL2011 study). In the European Healthcare Panel, a study performed by TNS Healthcare Inc. in the years 2007 to 2008 in a population of 240,005 subjects aged 18 to 69 years from six European countries (the United Kingdom, the Netherlands, Germany, France, and Italy), the rate of self-reported history of depression ranged from 
$31 \%$ in the Netherlands to $46 \%$ in France [8]. Similar findings (the rate of depression ranging from $31 \%$ in Austria to $47 \%$ in France) were obtained also for subjects aged 50 years and above in the SHARE study, conducted in 2005 using the EURO-D scale in representative populations of 10 European countries [9].

It is not surprising that DSs are more frequent in patients with chronic diseases. Depression is from twice to three times more prevalent in patients with, for example, diabetes [10] or CAD [11]. Not only do subjects with depression develop symptoms of CAD more often, but also DSs develop more frequently in the course of CAD. It has been estimated that about $20 \%$ of subjects with CAD meet the criteria of major depression, and mood disorders are seen in an even higher proportion of them [12]. These considerations may apply not only to CAD or MI but also to other conditions. In the NATPOL2011 study, DSs were more than twice more prevalent in subjects with CAD, diabetes, or a history of $\mathrm{MI}$ or stroke. Similar results were noted in the WOBASZ study [13]. Thus, it is important to perform careful screening for DSs in subjects with CAD, and particularly in those with a history of MI. Identification of major depression, reported to be present in $15 \%$ to $30 \%$ of patients within 18 months of an $\mathrm{MI}$, is of particular importance [14]. Despite a significantly higher rate of DSs in subjects with selected concomitant conditions in NATPOL2011, we did not confirm their independent association with these conditions except for previous stroke in women. Multiple studies suggest that DSs develop in about $30 \%$ of all stroke patients $[15,16]$. It has been estimated that for each 500,000 new stroke cases in the United States (US), DSs develop in about 150,000 subjects one year after the stroke [17]. In the 2002 MoVIES study, which included 1134 subjects, a significantly higher risk of clinically overt depression was found following a stroke, even two years or more after the acute event, and this risk was higher in women compared to men [18]. The US National Health and Nutrition Examination Survey (NHANES I), conducted in a representative sample of 10,025 subjects aged 25 to 74 years, showed that stroke was more common in women than in men, as well as in subjects with a lower level of education.

Similarly to the NATPOL2011 study, a meta-analysis of studies published in 1980-2005, which included 51,331 subjects, revealed that DSs were about twice more prevalent in subjects with type 2 diabetes [19]. A British study in 800 Caucasians aged 40 to 75 years and 290 Asians aged 25 to 75 years found no association between DSs (evaluated using the WHO-5 and CES-D scales) and type 2 diabetes, regardless of age, sex, and ethnic differences, again similarly to the present analysis [19].

The NATPOL2011 study results indicate that DSs were related to age and the education level of the study subjects. A higher prevalence of DSs in older subjects compared to the younger ones may result from increasing age-related social problems, disability, and loneliness. Limitations resulting from cerebral dysfunction and progressive atherosclerosis may also be of importance. A simple association between increasing DSs and age is not always apparent. In the multinational World Health Organization Composite International Diagnostic Interview (WHO CIDI) study, which included 89,037 subjects from 18 countries, a large variation in the prevalence of DSs in various age groups was found between countries of different wealth [20]. In rich countries such as the US, New Zealand, Japan, France, or Germany, DSs were nearly four times as prevalent in younger age groups (18-34 years) as in older subjects (above 64 years of age), while an opposite correlation, with more frequent DSs in older age groups, was found in poorer countries including the Ukraine, India, and Mexico.

The level of education is commonly considered an important factor affecting the prevalence and severity of DSs. Multiple studies confirm a higher risk of depression among subjects with a lower level of education [20, 21]. In the population-based epidemiological Alameda County Study, which included 6928 California residents, depression was found to be much more prevalent among subjects with a low level of education compared to more educated subjects (OR 1.86, 95\% Cl 1.36-2.55) [22]. In the Consumers Survey conducted in a representative sample of 1423 men and women from 48 states in the US, depression was clearly more prevalent among subjects with a low education level and a low income, compared to those more educated and with a higher income [23]. The increase in depression with a lower level of education varies depending on the wealth of a given population. In the above-mentioned WHO CIDI study, the risk of depression among subjects with a low education level was as much as 14 times higher in India compared to high-income countries such as Germany, the Netherlands, and New Zealand [20]. Thus, a higher level of education in wealthy countries is not associated with a lower risk of depression.

In the NATPOL2011 study, it was not possible to clinically verify the diagnosis of DSs based on a single assessment using the BDI. In addition, we could not assess whether DSs preceded the occurrence of the evaluated concomitant conditions or resulted from these conditions.

In conclusion, the NATPOL2011 study found DSs in one-fifth of men and one-third of women aged 18 to 79 years. Depressive symptoms were significantly and independently associated with age, primary education level, and with a history of stroke in women.

It seems that DSs can influence the prevalence of CVDs. It is necessary to plan and to carry out follow-up studies taking into consideration the prevalence of DSs in the Polish population.

Funding: This study was partially funded by the Polish Ministry of Health as a publicly-funded project representing part 
of the National CVD Prevention and Treatment Programme (Narodowy Program Profilaktyki i Leczenia Chorób Układu Sercowo-Naczyniowego) and by statutory grants from the Medical University of Gdansk (ST-17; DZ.STAT.02-0128/07/137 GUMED) and the Medical University in Warsaw (grant WUM: 1WS/N/18). It was also partly funded by the following industry sponsors: the main sponsor of the project, Sanofi-Aventis - unrestricted educational grant; Abbott Laboratories Poland Ltd. - unrestricted educational grant; Siemens Ltd. - partner of the project - unrestricted educational grant; Polpharma - partner of the project - unrestricted educational grant - to part of the project dedicated to heart failure. The funding agencies had no involvement in the design or conduct of the study, the collection, management, analysis, and interpretation of the data, or in the drafting of the manuscript.

\section{Conflict of interest: none declared}

\section{References}

1. General Statistical Office, Branch Yearbooks, Demographic Year-book of Poland. 2012: Warsaw.

2. Rozanski A, Blumenthal JA, Davidson KW, et al. The epidemiology, pathophysiology, and management of psychosocial risk factors in cardiac practice: the emerging field of behavioral cardiology. J Am Coll Cardiol. 2005; 45(5): 637-651, doi: 10.1016/j. jacc.2004.12.005, indexed in Pubmed: 15734605.

3. Ford ES, Ahluwalia IB, Galuska DA. Social relationships and cardiovascular disease risk factors: findings from the third national health and nutrition examination survey. Prev Med. 2000; 30(2): 83-92, doi: 10.1006/pmed.1999.0606, indexed in Pubmed: 10656835.

4. Pratt LA, Ford DE, Crum RM, et al. Depression, psychotropic medication, and risk of myocardial infarction. Prospective data from the Baltimore ECA follow-up. Circulation. 1996; 94(12): 3123-3129, indexed in Pubmed: 8989119.

5. Zdrojewski T, Rutkowski M, Bandosz P, et al. Prevalence and control of cardiovascular risk factors in Poland. Assumptions and objectives of the NATPOL 2011 Survey. Kardiol Pol. 2013; 71(4): 381-392, doi: 10.5603/KP.2013.0066, indexed in Pubmed: 23788344.

6. Beck AT, Steer CH, Mendelson M, et al. An inventory for measuring depression. Arch Gen Psychiatry. 1961; 4(6): 561-571, doi: 10.1001/archpsyc.1961.01710120031004.

7. Piwoński J, Piwońska A, Głuszek J, et al. The prevalence of low social support level and depressive symptoms in Polish population. The results of WOBASZ study]. Kardiol Pol. 2005; 63(suppl. 4): S645-S648.

8. Narayanan S, Potthoff P, Guether B. PMH4. Prevalence of depression in Europe: a comparison of five countries. Value in Health. 2009; 12(3): A173, doi: 10.1016/s1098-3015(10)73926-7.
9. Castro-Costa E, Dewey M, Stewart R, et al. Prevalence of depressive symptoms and syndromes in later life in ten European countries: the SHARE study. Br J Psychiatry. 2007; 191: 393-401, doi: 10.1192/bjp.bp.107.036772, indexed in Pubmed: 17978318. 10. Anderson RJ, Freedland KE, Clouse RE, et al. The prevalence of comorbid depression in adults with diabetes: a meta-analysis. Diabetes Care. 2001; 24(6): 1069-1078, doi: 10.2337/diacare.24.6.1069, indexed in Pubmed: 11375373.

11. Rudisch B, Nemeroff CB. Epidemiology of comorbid coronary artery disease and depression. Biol Psychiatry. 2003; 54(3): 227-240, doi: 10.1016/S0006-3223(03)00587-0, indexed in Pubmed: 12893099.

12. Parissis JT, Fountoulaki K, Filippatos G, et al. Depression in coronary artery disease: novel pathophysiologic mechanisms and therapeutic implications. Int J Cardiol. 2007; 116(2): 153-160, doi: 10.1016/.ijcard.2006.03.038, indexed in Pubmed: 16822560.

13. Piwoński J, Piwońska A, Sygnowska E. Is there an association between depressive symptoms and coronary artery disease in the Polish adult population? Kardiol Pol. 2014; 72(1): 50-55, doi: 10.5603/KP.a2013.0149, indexed in Pubmed: 23799622.

14. Strik JJ, Honig A, Maes M. Depression and myocardial infarction: relationship between heart and mind. Prog Neuropsychopharmacol Biol Psychiatry. 2001; 25(4): 879-892, doi: 10.1016/S02785846(01)00150-6, indexed in Pubmed: 11383983.

15. Williams LS. Depression and stroke: cause or consequence? Semin Neurol. 2005; 25(4): 396-409, doi: 10.1055/s-2005-923534, indexed in Pubmed: 16341996.

16. Rosamond W, Flegal K, Friday G, et al. Heart Disease and Stroke Statistics-2007 update: a report from the American Heart Association Statistics Committee and Stroke Statistics Subcommittee. Circulation. 2007; 115(5), doi: 10.1161/circulationaha.106.179918.

17. Ellis C, Zhao Y, Egede LE. Depression and increased risk of death in adults with stroke. J Psychosom Res. 2010; 68(6): 545-551, doi: 10.1016/j.jpsychores.2009.11.006, indexed in Pubmed: 20488271.

18. Whyte EM, Mulsant BH, Vanderbilt J, et al. Depression after stroke: a prospective epidemiological study. J Am Geriatr Soc. 2004; 52(5): 774-778, doi: 10.1111/j.1532-5415.2004.52217.x, indexed in Pubmed: 15086660.

19. Aujla N, Skinner TC, Khunti K, et al. The prevalence of depressive symptoms in a white European and South Asian population with impaired glucose regulation and screen-detected Type 2 diabetes mellitus: a comparison of two screening tools. Diabet Med. 2010; 27(8): 896-905, doi: 10.1111/j.1464-5491.2010.03042.x, indexed in Pubmed: 20653747.

20. Bromet E, Andrade LH, Hwang I, et al. Cross-national epidemiology of DSM-IV major depressive episode. BMC Med. 2011; 9: 90, doi: 10.1186/1741-7015-9-90, indexed in Pubmed: 21791035.

21. Tylka J, Sztynar K. Temperamental correlates of the intensity of depression in women]. Studia Psychol. 2009; 9: 139-147.

22. Kaplan GA, Roberts RE, Camacho TC, et al. Psychosocial predictors of depression. Prospective evidence from the human population laboratory studies. Am J Epidemiol. 1987; 125(2): 206-220, indexed in Pubmed: 3812429.

23. Toussaint LL, Williams DR, Musuc MA, et al. Forgiveness and health: age differences in a US probability sample. J Adult Dev. 2001; 8: 249-259, doi: 10.1023/A: 1011394629736.

Cite this article as: Piwoński J, Piwońska A, Jędrusik P, et al. Depressive symptoms and cardiovascular diseases in the adult Polish population. Results of the NATPOL2011 study. Kardiol Pol. 2019; 77(1): 18-23, doi: 10.5603/KP.a2018.0213.

\section{WHAT IS NEW?}

This is the first study examining the epidemiology of depressive symptoms in a random sample of adults in Poland in this decade. The results of the NATPOL2011 survey revealed that the prevalence of depressive symptoms is still very high; they refer to every fifth man and every third woman. We showed that depressive symptoms are independently associated with age, primary education, and a history of stroke in women. High prevalence and potential impact of depressive symptoms on prognosis in patients with cardiovascular diseases call for follow-up projects in cardiovascular diseases to be carried out in Poland. 